\title{
ANALISA PENDAPATAN USAHA TANI APEL (Malus Sylvester Mill) DI KABUPATEN PASURUAN (Studi Kasus Desa Andonosari Kecamatan Tutur Kabupaten Pasuruan)
}

\section{Analysis Of Application Farming Income (Malus Sylvester Mill) In Pasuruan District (Case Study of Andonosari Village, Tutur District, Pasuruan Regency)}

\author{
Ilmiatul Imama ${ }^{1}$, Novi Istna Hidayati ${ }^{1}$ \\ Program Studi Agribisnis, Fakultas Pertanian, Universitas Yudharta Pasuruan \\ Email :noviitsna@yahoo.com
}

\begin{abstract}
ABSTRAK
Apel (Malus Sylvester Mill) merupakan tanaman buah tahunan yang salah satu komoditas hortikultura daerah subtropis atau daratan tinggi yang memiliki prospek yang sangat baik untuk dikembangkan sekarang dan di masa yang akan datang. Desa Andonosari Kecamatan Tutur Kabupaten Pasuruan merupakan kebun apel terbesar di Indonesia. Tujuan penelitian ini adalah untuk bisa mengalisis biaya yang di keluarkan, menganalisis pendapatan yang akan di terima serta menganalisis tingkat nilai efisiensi usaha tani apel di Desa Andonosari Kecamatan Tutur Kabupaten Pasuruan. Metode yang digunakan dalam penelitian ini adalah regresi deskpritif. Alasan utama peneliti menggunakan metode ini karena ingin mengetahui adanya pendapatan, pengeluaran dan efensiensi dalam bercocok tanam tanaman apel yang berada di Desa Andonosari Kecamatan Tutur Kabupaten Pasuruan. Hasil penelitian terbukti bahwa usaha tani apel yang dijalankan pada musim panen masih menguntungkan untuk dilaksanakan. Usaha tani apel dapat dikatakan belum baik, apabila terbukti bahwa sejauh ini petani belum memanfaatkan input produksi secara maksimal untuk peningkatan produksi. Nilai R/C rasio yang lebih besar dari satu menunjukan bahwa usaha tani apel di Desa Andonosari saat ini layak untuk diusahakan. Kesimpulan dari penelitian adalah nilai $\mathrm{R} / \mathrm{C}$ rasio menunjukkan bahwa petani apel memperoleh $>1$, artinya usaha tani apel tergolong efisiensi dan menguntungkan. Hal ini dapat dibuktikan bahwa nilai $\mathrm{R} / \mathrm{C}$ rasio atas biaya yang dikeluarkan pada apel Manalagi 3. Adapun saran yang di berikan penulis adalah (1) Petani seharusnya bisa memperbaiki usaha tani yang dikelola saat ini. (2) Petani harus lebih memahami tentang biaya - biaya usaha tani dan mengetahui hal hal yang terdapat di usaha tani apel. (3) Untuk meningkatkan harga jual diharapkan petani dapat meningkatkan kualitas buah khususnya dalam keseragaman ukuran.

Kata kunci: Apel, Pendapatan, Usaha Tani,

ABSTRACT

Apple (Malus Sylvester Mill) is an annual fruit plant which is one of the horticultural commodities in the sub-tropics or high land which has very good prospects to be developed now and in the future. Andonosari Village, Tutur Subdistrict, Pasuruan Regency is the largest apple orchard in Indonesia. The purpose of this study is to be able to analyze the costs incurred, analyze the income to be received and analyze the level of value of efficiency of apple farming in Andonosari Village, Tutur District,
\end{abstract}


Pasuruan Regency. The method used in this study is descriptive regression. The main reason researchers used this method was because they wanted to know the existence of income, expenditure and efficiency in growing apple plants in Andonosari Village, Tutur Sub-District, Pasuruan Regency. The results of the research proved that apple farming carried out during the harvest season was still profitable to implement. Apple farming can be said to be not good, if it is proven that so far farmers have not utilized production inputs maximally to increase production. $R$ / C ratio greater than one shows that apple farming in Andonosari Village is currently feasible to cultivate. The conclusion of the study is that the $R / C$ ratio shows that apple farmers get $>1$, meaning that apple farming is classified as efficient and profitable. This can be proven that the $R$ I $C$ ratio is the cost incurred in Manalagi apples 3. The suggestions given by the author are (1) Farmers should be able to improve the farms currently managed. (2) Farmers must understand more about farming costs and know things that are found in apples. (3) To increase selling prices, farmers are expected to be able to improve the quality of fruit, especially in uniformity in size

Keywords: Apple, Farming, Revenue

\section{PENDAHULUAN}

Indonesia merupakan negara agraris yang artinya Negara kita berperan penting dalam sektor pertanian yang sebagian besar penduduknya berprofesi dengan usaha tani. Sektor pertanian sendiri memiliki beberapa subsektor, antara lain subsektor tanaman pangan atau tanaman bahan makanan (lebih dikenal dengan pertanian rakyat), subsektor perkebunan, subsektor peternakan, subsektor perikanan, serta subsektor kehutanan. Indonesia merupakan satu negara yang cocok untuk subsektor perkebunan, karena pada umumnya perkebunan berada di daerah bermusim dingin atau di daerah khatulistiwa (Devi Permatasari, 2014)

Apel (Malus Sylvester Mill) merupakan tanaman buah tahunan yang salah satu komoditas hortikultura daerah sub-tropik atau daratan tinggi yang memiliki prospek yang sangat baik untuk dikembangkan sekarang dan di masa yang akan datang. Hal ini dikarenakan di Indonesia baru hanya ada dua provinsi penghasil apel yaitu Jawa Timur dan Nusa Tenggara Timur. Di Jawa Timur, yang selama ini dikenal sebagai sentra produksi apel di Indonesia, perkembangan tanaman apel terfokus di kabupaten Pasuruan di mana promosi jumlah luas lahan buah apel mencapai sekitar $625 \mathrm{Ha}$ dari luas lahan apel di yang bersangkutan. Daerah produksi apel di provinsi Jawa Timur selain Pasuruan adalah Malang, Probolinggo dan Bondowoso. Menurut Fredi Kurniawan (2016) morfologi tanaman apel yaitu:

\section{Akar}

Tanaman apel memiliki akar tunggang yaitu akar bawah tegak lurus ke dalam tanah berfungsi untuk menyokong tanaman, menyerap unsur hara tanah.

\section{Batang}

Tanaman apel memiliki batang berkayu keras dan kuat. Tanaman ini memiliki kulit yang 
tebal, berwarna mudah, kecokelatan hingga kuning dan keabu-abuan.

\section{Daun}

Tanaman apel memiliki daun berbentuk long dan oval, memiliki ujung yang runcing dan memiliki kulit yang tebal, berwarna daun tumpul dan tepi daunnya bergerigi.

\section{Bunga}

Tanaman apel memiliki bunga bertangkai pendek, menghadap keatas, berdandan dan pada tiap tandan bunga memiliki 6-7 bunga. Bunga pada tanaman ini tumbuh di ketiak daun, mahkota daun berwarna putih dan kemerahan

\section{Buah}

Tanaman apel memiliki buah yang sangat bervariasi yaitu hijau, merah, kekuningan dan juga kemerahan dengan bentuk oval atau bulat. Buah pada apel memiliki kulit tipis dan kasar serta memiliki pori-pori yang besar. Namun, setelah matang sempurna akan menjadi mengkilat dan juga halus permukaan buah.

Desa Andonosari Kecamatan Tutur Kabupaten Pasuruan merupakan kebun apel terbesar di Indonesia. Daerah ini juga sangat cocok untuk tanaman hortikultura, seperti sayur-sayuran, buah-buahan, dan tanaman hias (Murdijati Gardjito, 2015). Bermacammacam jenis apel terdapat di daerah ini, antara lain: apel manalagi, apel rhome beauty, apel anna dan apel wanle. Selain apel juga terdapat paprika dan bunga krisan.
Jumlah permintaan terhadap buah apel akan terus meningkat seiring dengan pertambahan jumlah penduduk, namun hal ini akan menjadi suatu masalah jika terdapat kesenjangan antara jumlah ketersediaan dan permintaan buah apel. Oleh karenan itu upaya peningkatan produksi buah apel perlu ditingkatkan guna mengatasi kesenjangan tersebut. Adapun peningkatan produksi buah apel di Indonesia dari tahun ke tahun dapat dilihat pada Tabel 1.

Tabel 1. Luas Area, Produktivitas, Produksi buah apel di kecamatan Tutur tahun 2011-2014

\begin{tabular}{ccccc}
\hline No & Tahun & Luas Area & $\begin{array}{c}\text { Produkti } \\
\text { vitas }\end{array}$ & $\begin{array}{c}\text { Produk } \\
\text { si }\end{array}$ \\
\hline 1. & 2011 & $5.587,60$ & 7.157 & 7.157 \\
2. & 2012 & 5.587 .60 & 7.157 & 7.157 \\
3. & 2013 & $5.587,60$ & 8438 & 8438 \\
4 & 2014 & $5.587,60$ & 8047 & 8462 \\
\hline
\end{tabular}

Sumber: Data BPS Pasuruan Tahun 20112014

Dengan luas lahan yang cukup luas, kabupaten Pasuruan mempunyai potensi yang cukup besar dalam mengembangkan produksi buah apel salah satunya Desa Andonosari Kecamatan Tutur Kabupaten Pasuruan. Apel merupakan sumber pendapatan sebagian besar penduduk disamping kegiatan lainnya. Hal ini tidak terlepas dari adanya peranan pemerintah setempat yang senantiasa memberikan bimbingan dan bantuan kepada para petani agar produksinya dapat ditingkatkan sehingga pendapatan usaha tani apel juga meningkat.

Sampai saat ini informasi mengenai efisiensi dan permasalahan pendapatan usaha tani apel di Desa Andonosari masih terbatas, 
sedangkan hasil dari analisis pendapatan usaha tani apel ini menunjukan apakah usaha tani apel layak atau tidak layak untuk di kembangkan. Informasi ini berguna bagi para petani maupun investor yang tertarik untuk mengembangkan atau menanamkan modalnya dalam usaha tani apel. Sehingga dengan adanya investasi dalam pengembangan usaha tani ini diharapkan meningkatkan jumlah produksi apel dan pada akhirnya meningkatkan keuntungan atau pendapatan petani dan investor itu sendiri.

\section{Perumusan Masalah}

1. Berapa besar biaya yang di keluarkan usaha tani apel di Desa Andonosari Kecamatan Tutur Kabupaten Pasuruan?

2. Berapa besar pendapatan yang akan di terima usaha tani apel di Desa Andonosari Kecamatan Tutur Kabupaten Pasuruan?

3. Berapa besar tingkat nilai efisiensi usaha tani apel di Desa Andonosari Kecamatan Tutur Kabupaten Pasuruan?

\section{Tujuan Penelitian}

1. Analisis biaya yang di keluarkan usaha tani apel di Desa Andonosari Kecamatan Tutur Kabupaten Pasuruan.

2. Analisis pendapatan yang akan di terima usaha tani apel di Desa Andonosari Kecamatan Tutur Kabupaten Pasuruan.
3. Menganalisis tingkat nilai efisiensi usaha tani apel di Desa Andonosari Kecamatan Tutur Kabupaten Pasuruan.

\section{METODE PENELITIAN}

\section{Lokasi dan Waktu Penelitian}

Penelitian ini dilakukan di Desa Andonosari Kecamatan Tutur Kabupaten Pasuruan Jawa Timur. Pemilihan lokasi ini dilakukan secara sengaja (Purposive) atas pertimbangan memilih Desa Andonosari Kecamatan Tutur adalah karena desa tersebut memiliki luas lahan tanaman apel dan produksi tanaman apel yang paling besar di antara desa-desa lain yang ada di Kecamatan Tutur. Penelitian ini dilakukan pada bulan Juni 2017 dan waktu yang digunakan untuk memperoleh data dan keterangan dari petani dan semua pihak yang bersangkutan.

\section{Metode Pengambilan Sampel}

Teknik yang digunakan dalam penelitian ini adalah teknik survei yang dilakukan dengan menggunakan sampel dengan menggunakan kuisioner. Penentuan populasi yang digunakan yaitu petani yang menjadi sampel penelitian menggunakan secara sengaja (purposive sampling. Dengan pertimbangan desa-desa dan data dari BPS (Badan Pusat Statistik) yang memiliki usaha tani tanaman apel terbanyak adalah Desa Andonosari Kecamatan Tutur Kabupaten Pasuruan.

\section{Metode Pengambilan Data}


Pengumpulan data yang dilakukan dengan menggunakan data sekunder dan data primer. Data sekunder di dapatkan mengumpulkan catatan-catatan serta dokumentasi dari pihak atau instansi yang terkait dengan usaha tani tanaman apel, sedangkan data primer di dapatkan dari hasil wawancara responden in-depth interview berdasarkan daftar pertanyaan (kuesioner) yang telah disiapkan.

\section{Metode Analisis Data}

Data yang diperoleh yaitu berupa data primer dan sekunder yang akan dianalisis secara kualitatif dan kuantitatif. Analisis kualitatif digunakan untuk melihat kegiatan produksi atau usaha tani tanaman apel Desa Andonosari Kecamatan Tutur Kabupaten Pasuruan dan memerlukan bantuan gambar untuk memperjelas uraian serta ada beberapa hal yang terkait akan diuraikan secara deskritif. Deskriptif merupakan suatu metode dalam penelitian status kelompok manusia, suatu obyek, suatu kondisi, suatu sistem pemikiran ataupun suatu kelas peristiwa pada masa sekarang (Putri, 2015).

\section{A. Analisis Biaya Pengeluaran Usaha tani Apel}

Biaya total adalah seluruh biaya yang dikeluarkan karena terpakainya faktor-faktor produksi dalai proses produksi yang terdiri dari biaya tetap dan biaya variabel.

Untuk mengetahui total biaya yang dikeluarkan dalai usaha tani menurut
Agustina Shinta (2011) adalah sebagai berikut:

$$
\mathbf{T C}=\mathbf{T F C}+\mathbf{T V C}
$$

Keterangan:

TC = Biaya Total $/$ Total Cost (Rp)

TFC = Total Biaya Tetap / Total Fixed Cost (Rp)

TVC = Total Biaya Variabel /

Total Variabel Cost (Rp)

\section{B. Analisis Pendapatan Usaha tani Apel}

Untuk mengetahui analisis pendapatan usaha tani apel ini dilakukan pencatatan terhadap seluruh biaya pengeluaran, pendapatan serta keuntungan kegiatan produksi tanaman apel mulai dari awal proses sampai pasca panen dalam satu musim tanam. Data pengeluaran biaya dibagi 2 bagian, yaitu: biaya tunai dan biaya tidak tunai. Untuk melakukan perhitungan pendapatan usaha tani tanaman apel atas biaya tunai atau pendapatan kotor dan perhitungan pandapatan usaha tani atas biaya total atau pendapatan bersih. Adapun rumus perhitungan sebagai berikut:

1. Penerimaan usaha tani apel dihitung dengan rumus:

$\mathbf{T R}=\mathbf{P y} \cdot \mathbf{Y}$

Keterangan:

TR= Penerimaan

$\mathbf{P y}=$ harga produksi $(\mathrm{Rp} / \mathrm{Kg})$

$\mathbf{Y}=$ jumlah produksi $(\mathrm{Kg})$

(Sumber: Suratiyah, 2008)

2. Pendapatan usaha tani apel adalaha selisih antara penerimaan dan semua 
biaya usaha tani apel. Pendapatan usaha tani apel dihitung dengan rumus:

$\Pi=\mathbf{T R}-\mathbf{T C}$

(2)

Keterangan:

$\boldsymbol{\pi}=$ pendapatan usaha tani apel

$\mathbf{T R}=$ total penerimaan usaha tani apel

$\mathbf{T C}=$ total biaya usaha tani apel

(Sumber: Umi Barokah, 2014)

\section{Analisis Biaya $\mathrm{R} / \mathrm{C}$ rasio}

Analisis biaya R/C rasio merupakan perbandingan antara nilai output terhadap nilai inputnya atau perbandingan penerimaan yang diperoleh petani dari setiap jumlah pengeluaran untuk usaha taninya yang di manfaatkan. Data analisis tersebut penerimaan usaha tani dan pengeluaran usaha tani dibandingkan dalam satu rasio.

Dalam penelitian ini, untuk mengetahui efisiensi usaha dari suatu usaha tani dapat menggunakan $\mathrm{R} / \mathrm{C}$ rasio dengan rumus sebagai berikut:

$\mathrm{R} / \mathrm{C}$ rasio $=\frac{\mathrm{TR}}{\mathrm{TC}}$.

Keterangan :

TR= total penerimaan usaha tani

TC = total biaya usaha tani

Analisis ini digunakan untuk melihat keuntungan dan kelayakan usaha tani. Adapun kriteria keputusan yang digunakan untuk melihat hasil keuntungan $\mathrm{R} / \mathrm{C}$ rasio adalah sebagai berikut:

$\mathrm{R} / \mathrm{C}$ rasio $>1=$ usaha tani menguntungkan $\mathrm{R} / \mathrm{C}$ rasio $=1=$ usaha tani tetap
$\mathrm{R} / \mathrm{C}$ rasio $<1=$ usaha tani merugikan

$\mathrm{R} / \mathrm{C}$ rasio > 1 dikatakan efisiensi karena setiap tambahan biaya yang dikeluarkan akan menghasilkan tambahan penerimaan yang lebih besar lagi. Sedangkan apabila $\mathrm{R} / \mathrm{C}$ rasio $=1$ maka dikatakan kegiatan usaha tani berada pada kondisi tetap (tidak rugi dan tidak untung). Dan apabila $\mathrm{R} / \mathrm{C}$ rasio $<1$ maka usaha tani ini dikatakan tidak efisiensi karena setiap biaya yang dikeluarkan menghasilkan tambahan penerimaan yang lebih kecil. Usaha ini dikatakan menguntungkan dan layak apabila nilai $\mathrm{R} / \mathrm{C}$ ratio lebih dari 1 . Hal ini menunjukkan setiap nilai rupiah yang dikeluarkan dalam prosuksi akan memberikan manfaat sejumlah nilai penerimaan yang diperoleh.

\section{HASIL ANALISIS DAN PEMBAHASAN}

\section{Analisis Biaya Pengeluaran Usaha Tani Apel}

Pengeluaran (expenditure) atau biaya produksi adalah keseluruhan biaya yang di gunakan dalam satu proses produksi yang berlangsung dalam sekali panen atau setengah tahun untuk memperoleh beberapa keuntungan. Biaya produksi terdiri dari biaya tetap dan biaya tidak tetap. Pada usaha tani apel di Desa Andosari Kecamatan Tutur Kabupaten Pasuruan, Biaya tetap meliputi biaya penyusutan, meliputi: penyusutan tempat, bibit, dan peralatan, sedangkan biaya 
tidak tetap meliputi obat-obatan, pupuk kimia, pupuk oganik, tenaga kerja.

Tabel. 2 Biaya pengeluaran usaha tani apel di Desa Andonosari Kecamatan Tutur Kabupaten Pasuruan/Thn/Ha.

\begin{tabular}{ccc}
\hline No & Jenis Biaya & Nilai \\
\hline 1 & Pupuk Kadang & Rp. 5.274 .333 \\
2 & Pupuk Kimia & Rp. 15.437 .686 \\
3 & Obat - obatan & Rp. 20.092 .583 \\
4 & Tenaga Kerja & Rp. 3.181 .611 \\
5 & Penyusutan & Rp. 4.627 .222 \\
\hline & Total Biaya & Rp. 48.613.435
\end{tabular}

Sumber data: Data Primer 2017

Pada tabel 20 dapat di lihat bahwa ratarata biaya terbesar adalah biaya untuk pembelian pupuk kimia yaitu sebesar Rp. 15.437.686 dan pupuk kadang sebesar Rp. 5.274.333. Penggunaan pupuk sangat mempengaruhi dalam peningkatan produksi, dengan luas lahan yang berfariasi dan tingkat kesuburan tanah yang berbeda-beda maka untuk rata - rata penggunaan pupuk dalam satu kali musim tanam dan 2 kali musim tanam berbeda.

Sedangkan yang di keluarkan untuk tenaga kerja Rp. 3.181.611 dengan jumlah tenaga kerja yang dibutuhkan sebanyak 20 orang dan upah yang diterima setiap orang adalah Rp. 50.000. Hal ini penggunaan tenaga kerja yang di gunakan dalam 1 kali musim tanam dan 2 kali musim tanam berbeda rata-rata pengeluarannya karena hasil produksi usaha tani yang berbeda beda pada saat musim panen. Biaya yang dikeluarkan untuk pembelian obat-obatan yaitu sebesar Rp. 20.092.583. Hal ini di sebabkan karena hama dan penyakit yang menyerap setiap apel sangat tinggi.

Pengeluaran tunai dalam usaha tani apel meliputi pupuk kandang, pupuk kimia (NPK, Urea, Ponska), tenaga kerja, obat - obatan (baik padat atau cair). Sedangkan yang termasuk biaya tidak tetap adalah biaya penyusutan alat sebesar Rp. 4.627.222.

\section{Analisis Pendapatan Usaha Tani Apel}

Pendapatan usaha tani adalah selisih antara penerimaan dengan semua biaya yang dikeluarkan selama menanam. Apabila nilai selisih negatif maka pendapatan petani adalah rugi namun sebaliknya jika selisih positif maka dikatakan usaha tani menguntungkan.

Harga apel yang terjadi pada saat panen dapat dipengaruhi dengan kualitas apel sendiri dan mekanisme pasar. Pada saat musim hujan tanaman apel produktivitas sangat rendah, tetapi pada musim kemarau produktivitas tanaman apel sangat tinggi. Di samping itu juga, tanaman apel juga bisa ditentukan dengan datangnya buah tahunan, seperti buah durian, alpukat, jeruk, rambutan dan lain - lain. Pada saat datangnya panen buah tahunan bersamaan dengan panen buah apel menyebabkan harga produksi apel sangat rendah. Hal ini karena harga apel mengalami fluktuasi.

Tabel. 3 Biaya pendapatan usaha tani apel di Desa Andonosari Kecamatan Tutur Kabupaten Pasuruan/Thn/Ha.

\begin{tabular}{llc}
\hline NO & Manalagi & Total \\
\hline 1 & Total Biaya & Rp. 160.813 .972 \\
\hline
\end{tabular}


2 Penerimaan Rp. 363.694 .444

3 Pendapatan Rp. 235.574.472

Sumber data: Data Primer 2017

Berdasarkan data yang di dapatkan total penerimaan dan pendapatan usaha tani apel apel Manalagi rata-rata sebesar 9.757/kg. Hasil panen tanaman apel Manalagi menghasilkan total produksi rata - rata sebesar Rp. 363.694.444 per hektar. Penerimaan jumlah apel berbeda, karena meningkatnya jumlah produktifitas apel yang relatif berbeda. Sedangkan pendapatan yang diperoleh usaha tani apel manalagi sebesar Rp. 235.574.472 dengan total biaya yang dikeluarkan sebesar Rp. 160.813.972. pada umumnya usaha tani apel Manalagi, Merah, Anna dan Royal Red memiliki biaya produksi yang sama.

\section{Analisis Tingkat Nilai Efisiensi Usaha Tani}

Apel

Analisis penerimaan dan biaya R/C rasio usaha tani apel di Desa Andonosari Kecamatan Tutur Kabupaten Pasuruan yang diusahakan petani responden, menunjukkan bahwa usaha tani yang dijalankan memiliki penerimaan yang lebih besar daripada biaya yang di keluarkan dalam usaha tani. Hal ini dapat dibuktikan bahwa nilai $\mathrm{R} / \mathrm{C}$ rasio lebih dari satu. Nilai R/C rasio atas biaya yang dikeluarkan pada apel Manalagi sebesar 3. Nilai R/C rasio atas biaya yang dikeluarkan cukup sedikit, karena dalam melakukan usaha tani apel seluruh petani responden tidak mengeluarkan biaya lebih banyak.
Dengan demikian keefisiensi dapat dibuktikan bahwa pendapatan usaha tani apel Manalagi 3 maka $\mathrm{R} / \mathrm{C}$ rasio $>1=$ usaha tani yang menguntungkan dan juga di katakan usaha tani apel ini efisiensi.

\section{KESIMPILAN}

Berdasarkan analisis biaya yang dikeluarkan usaha tani apel menunjukkan bahwa dalam pengusaha apel di daerah peneliti mengeluarkan biaya sebesar Rp. 160.813.972. Total biaya yang dikeluarkan usaha tani apel tidak dapat mempengarui varietas tanaman apel yang lainnya, seperti: apel Manalagi, Merah, Anna dan Royal Red.

Berdasarkan analisis pendapatan usaha tani apel di Daerah peneliti sangat menguntungkan. Rata - rata pendapatan usaha tani apel Manalagi sebesar Rp. 235.574.472dengan jumlah penerimaan sebesar Rp. 363.694.444. Dalam hal ini menunujukkan bahwa rata - rata penerimaan yang diperoleh petani dapat menutupi keseluruhan biaya yang dikeluarkan dan selebihnya merupakan keuntungan yang di dapat olah petani apel.

Hasil analisis efisiensi dengan menggunakan $\mathrm{R} / \mathrm{C}$ rasio menunjukkan bahwa petani apel memperoleh $>1$, artinya usaha tani apel tergolong efisiensi dan menguntungkan. Hal ini dapat dibuktikan bahwa nilai $\mathrm{R} / \mathrm{C}$ rasio atas biaya yang dikeluarkan pada apel Manalagi sebesar 3.

\section{DAFTAR PUSTAKA}


Barokah, Umi, dkk. (2014). Analisis Biaya dan Pendapatan Usaha tani Padi di Kabupaten Karanganyar. Jurnal AGRIC. Volume 26 Nomor $1 \& 2$. Hal 13-14.

Permatasari, Devi. (2014). Analisis Pendapatan Usaha tani Gula Tumbu (Kasus Kecamatan Dawe Kabupaten Kudus). Semarang .

Putri, Erryka Aprilia, dkk. (2015). Analisis Pendapatan Efensiensi Biaya Usaha tani Tembakau Maesan 2 di Kabupaten Bondowoso. Jurnal JSEP. Volume 8 Nomor 1. Hal 65.
Sugiono, (2015). Metode Penelitian Kuantitatif Kualitatif dan $R \& D$. Bandung. Alfabeta.

Suratiyah, Ken. (2008). Ilmu Usaha tani. Jakarta. Penebar Swadaya. 2015). Ilmu Usaha tani (edisi revisi). Jakarta. Penerba Swadaya.

Shinta, agustina. (2011). Ilmu Usaha tani. Universitas Brawijaya Press, Malang.

Kurniawan, Fredi. (2016). Klasifikasi dan Morfologi Tanaman Tomat (online): http://fredikur.niawan.com / klasifikasi dan morfologi tanaman tomat/. Diakses 1 Juni 2017 